\title{
Lost in Translation? Coping with Multiple Scanner Vendors in a Commercial Environment
}

\author{
David B. STEFAN ${ }^{1}$, David A. GILBERT ${ }^{2}$ \\ ${ }^{1}$ Novaptus Systems Inc., Chesapeake, VA, USA; \\ ${ }^{2}$ The Hague Plastic and Cosmetic Surgery Center, Norfolk, VA, USA \\ DOI: 10.15221/15.286 http://dx.doi.org/10.15221/15.286
}

\section{Introduction}

Changes in scanning technology and the emergence of additional scanner providers are, on the whole, a healthy sign for the industry. It gives users of scanning technology the choice of vendors, and minimizes the possibilities of becoming captive to a particular scanner manufacturer. However, with choice comes challenges in integrating a new scanner vendor into the existing production scanner network. Each vendor has their own measurement software with specific capabilities and it is not reasonable to operate multiple software measurement platforms in a production environment. By using a data modeling program that accepts multiple 3D formats, one can convert the various vendor scanner outputs into a common file format. A data utility program then converts these files to a format to be measured and processed on a commercial basis. In all conversions there are distortions. Quantifying this distortion is possible, but at best it can only be considered to be within an estimation range. The question is whether this distortion during the conversion process is significant.

The answer to this question, in part, depends on the particular scanning application. This network of scanners are used to document the measurements of preoperative morbidly obese individuals prior to, and after weight loss surgery. The morbidly obese are difficult to measure due to their unusual physical shapes. Their bodies undergo significant change as they experience massive weight loss. For the most part, accurate circumferential measurements are not as important as consistent measurement locations in order to document gross circumferential measurement changes.

However, if the scanning application mandates accurate circumferential measurements it would appear to be better served by using the software measurement package provided by the scanner manufacturer rather than converting the scan to another $3 \mathrm{D}$ format to be measured by another scanner manufacturer's measurement software.

\section{Methods}

The scanners in the network are not located near each other. It was not reasonable to ask a morbidly obese individual to get scanned at multiple locations, and even if that was possible the comparisons to be made between individual scanner measurements on a morbidly obese body would have variations beyond that of an individual that has a "typical" body shape.

For this reason, the author selected himself and his spouse as the subjects that were scanned in this paper.

The existing network consists of 3D booth type scanners from Sizestream and TC2. The booth scanners from TC2 are KX-16 and NX-16 models. Both the Sizestream and TC2 KX-16 scanners use near-field infrared lasers. As part of a commercial process, TC2 software is utilized to process the 3D body models from all scanners, including the Sizestream. To include body scans from Sizestream, two additional programs are used. The first imports the .obj file from the Sizestream scanner and subdivides the points comprising the .obj to create a denser body mesh. This file is then saved with a .wrl file extension. The TC2 Data Converter Utility then converts this .wrl file to a .bin format that can be opened within the TC2 KX-16 software measurement program.

Scans from the NX-16, which uses white light technology, need a TC2 utility program to convert the $\mathrm{NX}-16$.rbd file to the $\mathrm{KX}$-16-type .rbd file that the measurement software program requires. Binary files from the NX-16 can be loaded directly and converted to an .rbd file within the TC2 measurement software without the need of this conversion utility.

Multiple scans were taken of the same individuals using the Sizestream scanner. Multiple scans were taken of the same individuals using a TC2 NX-16 scanner. 
Two separate measurement systems were used to measure the scans acquired by the Sizestream scanner: The measurements provided by the Sizestream measurement software, and the measurements provided by the KX-16 measurement software after the Sizestream scan was converted to KX-16 .binary format.

This provides a comparison between using the Sizestream measurement software and the TC2 KX16 measurement software.

The scans acquired by the NX-16 were processed as binary files within the KX-16 software, bypassing the need for the KX-16 conversion utility,

The measurement comparison matrix is shown in Table 1.

\begin{tabular}{|c|c|c|c|}
\hline Measurement Format & Sizestream .obj & $\begin{array}{c}\text { Sizestream converted to } \\
\text { TC2 KX-16.rbd }\end{array}$ & $\begin{array}{c}\text { TC2 KX-16 .rbd from } \\
\text { NX-16.binary }\end{array}$ \\
\hline Male & $\mathrm{x}$ & $\mathrm{x}$ & $\mathrm{x}$ \\
\hline Female & $\mathrm{x}$ & $\mathrm{x}$ & $\mathrm{x}$ \\
\hline
\end{tabular}

Table 1. Measurement Comparison Matrix

Three scans of each subject were successively taken using the Sizestream scanner. Three scans were taken using the TC2 NX-16 scanner.

A common extraction profile was created within each software measurement platform. Table 2 compares the extraction profiles and nomenclature used for TC2 and Sizestream.

The template produces circumferential measurement information only. This is the template that is applied in commercial practice to document the preoperative and postoperative circumferential measurements of individuals who underwent a weight loss surgical procedure.

In actual practice, another template is also applied to 3D body models created by the scanner that extracts torso volume, torso surface area, bulk volume and torso slices. These multidimensional extractions were not part of this straightforward comparison analysis.

\begin{tabular}{l|l|}
\hline TC2 Measurements, Inc & Sizestream Measurements, Inches \\
\hline Neck_Full & Neck Circumference \\
\hline Bust_Full & Bust Girth with Drop Tape \\
\hline Right_Biceps & Bicep Circum Right \\
\hline Right_Elbow & Elbow Circum Tape Right \\
\hline Right_Forearm & Forearm Circum Right \\
\hline Left_Biceps & Bicep Circum Left \\
\hline Left_Elbow & Elbow Circum Tape Left \\
\hline Left_Forearm & Forearm Circum Left \\
\hline Waist_Full & Waist Circumference \\
\hline Hips_Full & Hips Circumference \\
\hline Seat_Full & Seat Circumference \\
\hline Abdomen_Full & Abdomen Circumference \\
\hline Thigh_Left & Thigh Circum Left \\
\hline Thigh_Right & Thigh Circum Right \\
\hline Calf_Left & Calf Circum Left \\
\hline Calf_Right & Calf Circum Right \\
\hline Knee_Left & Knee Circum Left \\
\hline Knee_Right & Knee Circum Right \\
\hline
\end{tabular}

Table 2. Measurement Extraction Profile Comparisons between TC2 and Sizestream 
The measurement results for the male and female subjects were tabulated and compared. The first comparison was for the successive scans acquired by the individual machines as measured by the manufacturer's software measurement package. This gives a fair picture of the circumferential measurement consistency between successive scans on the same scanning platform.

The average of the measurements of the three sequential scans acquired by each machine was calculated, as was its standard deviation.

The Sizestream scans were then converted to a format that produced TC2 binary files. These were loaded into the KX 16 measurement software, converted to a measurable .rbd format and the TC2 measurement template was applied.

It must be noted that both the Sizestream and TC2 NX-16 were calibrated per manufacturer's procedures prior to acquiring the scans utilized in this analysis.

Both subjects attempted to be scanned in the same position during the scan acquisition process.

\section{Results}

Table 3 displays the measurement results from three sequential scans for a male as acquired and measured by the Sizestream scanner and the Sizestream measurement software.

\begin{tabular}{|l|c|c|c|c|c|}
\hline Sizestream Measurements, Inches & Scan 1 & Scan2 & Scan 3 & Average & Std Dev \\
\hline Neck Circumference & 19.23 & 17.93 & 18.77 & 18.64 & 0.66 \\
\hline Bust Girth with Drop Tape & 41.31 & 41.42 & 41.32 & 41.35 & 0.06 \\
\hline Bicep Circum Right & 13.92 & 13.93 & 13.96 & 13.94 & 0.02 \\
\hline Elbow Circum Tape Right & 11.60 & 11.76 & 12.18 & 11.85 & 0.30 \\
\hline Forearm Circum Right & 11.82 & 11.90 & 11.90 & 11.87 & 0.05 \\
\hline Bicep Circum Left & 13.61 & 13.83 & 13.33 & 13.59 & 0.25 \\
\hline Elbow Circum Tape Left & 11.60 & 12.17 & 11.91 & 11.89 & 0.29 \\
\hline Forearm Circum Left & 11.60 & 11.75 & 11.61 & 11.65 & 0.08 \\
\hline Waist Circumference & 38.30 & 38.36 & 38.23 & 38.30 & 0.07 \\
\hline Hips Circumference & 39.35 & 39.43 & 39.21 & 39.33 & 0.11 \\
\hline Seat Circumference & 38.65 & 38.82 & 38.68 & 38.72 & 0.09 \\
\hline Abdomen Circumference & 38.59 & 38.69 & 38.60 & 38.63 & 0.06 \\
\hline Thigh Circum Left & 21.48 & 21.65 & 21.32 & 21.48 & 0.17 \\
\hline Thigh Circum Right & 21.58 & 21.66 & 21.26 & 21.50 & 0.21 \\
\hline Calf Circum Left & 14.92 & 14.92 & 14.79 & 14.88 & 0.08 \\
\hline Calf Circum Right & 15.15 & 15.15 & 15.07 & 15.12 & 0.05 \\
\hline Knee Circum Left & 15.08 & 15.36 & 14.97 & 15.14 & 0.20 \\
\hline Knee Circum Right & 14.84 & 15.00 & 14.71 & 14.85 & 0.15
\end{tabular}

Table 3. Three Successive Scans of a Male Subject using the Sizestream Scanner and Sizestream Measurement Software

Inspection of Table 3 indicates some of the issues common with all 3D booth scanners in that the subject tried to stand in the same position as each scan was acquired, but inevitably, the position of the arms differed slightly between each scan. This resulted in different circumferential arm measurements, though the "Bicep Circumference Right" scan was consistent throughout the series. The neck measurements were quite different for each scan.

Table 4 displays the measurement results from the three sequential scans for a male as acquired by the TC2 NX-16 scanner and the TC2 KX-16 measurement software. Note that the binary file from the NX-16 was used to produce the .rbd file within the KX-16 software, bypassing the need for using the TC2 "RBDConverter" utility. 


\begin{tabular}{|l|c|c|c|c|c|}
\hline TC2 Measurements, Inches & Scan 1 & Scan 2 & Scan 3 & Average & Std Dev \\
\hline Neck_Full & 17.99 & 17.46 & 17.57 & 17.67 & 0.28 \\
\hline Bust_Full & 41.72 & 41.60 & 41.70 & 41.67 & 0.06 \\
\hline Right_Biceps & 13.92 & 13.32 & 13.58 & 13.61 & 0.30 \\
\hline Right_Elbow & 11.03 & 10.79 & 10.99 & 10.94 & 0.13 \\
\hline Right_Forearm & 11.80 & 11.50 & 11.58 & 11.63 & 0.15 \\
\hline Left_Biceps & 13.23 & 13.50 & 13.66 & 13.46 & 0.22 \\
\hline Left_Elbow & 10.79 & 10.67 & 10.63 & 10.69 & 0.08 \\
\hline Left_Forearm & 11.24 & 11.30 & 11.20 & 11.24 & 0.05 \\
\hline Waist_Full & 38.52 & 38.64 & 38.55 & 38.57 & 0.06 \\
\hline Hips_Full & 39.49 & 39.46 & 39.70 & 39.55 & 0.13 \\
\hline Seat_Full & 38.82 & 38.91 & 38.93 & 38.89 & 0.06 \\
\hline Abdomen_Full & 38.99 & 39.09 & 39.08 & 39.05 & 0.06 \\
\hline Thigh_Left & 22.25 & 22.31 & 22.56 & 22.37 & 0.16 \\
\hline Thigh_Right & 22.20 & 22.20 & 22.20 & 22.20 & 0.00 \\
\hline Calf_Left & 15.06 & 15.15 & 15.04 & 15.08 & 0.06 \\
\hline Calf_Right & 15.30 & 15.15 & 15.44 & 15.30 & 0.14 \\
\hline Knee_Left & 15.72 & 15.91 & 15.83 & 15.82 & 0.09 \\
\hline Knee_Right & 15.62 & 15.49 & 15.81 & 15.64 & 0.16 \\
\hline & & & & & \\
\hline
\end{tabular}

Table 4. Three Successive Scans of a Male Subject using the TC2 NX-16 Scanner and TC2 KX-16 Measurement Software

Table 4 shows a similar trend with the NX-16 scanner, particular for the circumferential arm measurements.

Table 5 depicts a "straight up" comparison with the measurement averages produced by the Sizestream scanner and the KX-16 scanner.

\begin{tabular}{|c|c|c|c|c|c|c|}
\hline & & Sizestream Average & TC2 NX-16 Average & & Sizestream & TC2 NX-16 \\
\hline & & Average & Average & Difference & STD DEV & STD DEV \\
\hline Sizestream Measurements, Inches & TC2 NX 16 & & & & & \\
\hline Neck Circumference & Neck_Full & 18.64 & 17.67 & -0.97 & 0.66 & 0.28 \\
\hline Bust Girth with Drop Tape & Bust_Full & 41.35 & 41.67 & 0.32 & 0.06 & 0.06 \\
\hline Bicep Circum Right & Right_Biceps & 13.94 & 13.61 & -0.33 & 0.02 & 0.30 \\
\hline Elbow Circum Tape Right & Right_Elbow & 11.85 & 10.94 & -0.91 & 0.30 & 0.13 \\
\hline Forearm Circum Right & Right_Forearm & 11.87 & 11.63 & -0.24 & 0.05 & 0.15 \\
\hline Bicep Circum Left & Left_Biceps & 13.59 & 13.46 & -0.13 & 0.25 & 0.22 \\
\hline Elbow Circum Tape Left & Left_Elbow & 11.89 & 10.69 & -1.20 & 0.29 & 0.08 \\
\hline Forearm Circum Left & Left_Forearm & 11.65 & 11.24 & -0.41 & 0.08 & 0.05 \\
\hline Waist Circumference & Waist_Full & 38.30 & 38.57 & 0.28 & 0.07 & 0.06 \\
\hline Hips Circumference & Hips_Full & 39.33 & 39.55 & 0.22 & 0.11 & 0.13 \\
\hline Seat Circumference & Seat_Full & 38.72 & 38.89 & 0.17 & 0.09 & 0.06 \\
\hline Abdomen Circumference & Abdomen_Full & 38.63 & 39.05 & 0.43 & 0.06 & 0.06 \\
\hline Thigh Circum Left & Thigh_Left & 21.48 & 22.37 & 0.89 & 0.17 & 0.16 \\
\hline Thigh Circum Right & Thigh_Right & 21.50 & 22.20 & 0.70 & 0.21 & 0.00 \\
\hline Calf Circum Left & Calf_Left & 14.88 & 15.08 & 0.21 & 0.08 & 0.06 \\
\hline Calf Circum Right & Calf_Right & 15.12 & 15.30 & 0.18 & 0.05 & 0.14 \\
\hline Knee Circum Left & Knee_Left & 15.14 & 15.82 & 0.69 & 0.20 & 0.09 \\
\hline Knee Circum Riaht & Knee Riaht & 14.85 & 15.64 & 0.79 & 0.15 & 0.16 \\
\hline
\end{tabular}

Table 5. A "Straight Up" Comparison of Measurements between Scans acquire by Sizestream and TC2 NX-16

Inspection of the "Difference" column in Table 5 depicts the variation between the average measurement values created by the Sizestream measurement software and the average measurement values created by the TC2 KX-16 measurement software that used scan images acquired by an NX-16 scanner. There are, of course, some differences. An interesting observation is that there appears to be no real pattern as to the difference measurement outcomes between the two scan sets. That is, one cannot say that either scanner measurement software overestimates or underestimates the whole SET of measurements applied to the 3D body models.

Table 6 displays the measurements of each Sizestream scan converted to TC2 binary format using the conversion process outlined earlier and measured by the measurement extraction profile within the TC2 KX-16 measurement software. 


\begin{tabular}{|l|c|c|c|c|c|}
\hline Measurements, Inches & Scan 1 & Scan 2 & Scan 3 & Average & STD DEV \\
\hline Neck_Full & 17.60 & 17.55 & 17.69 & 17.62 & 0.07 \\
\hline Bust_Full & 41.79 & 41.65 & 41.43 & 41.62 & 0.18 \\
\hline Right_Biceps & 13.62 & 13.61 & 13.57 & 13.60 & 0.03 \\
\hline Right_Elbow & 11.29 & 11.13 & 11.28 & 11.23 & 0.09 \\
\hline Right_Forearm & 11.46 & 11.50 & 11.53 & 11.50 & 0.04 \\
\hline Left_Biceps & 13.09 & 13.22 & 12.91 & 13.07 & 0.15 \\
\hline Left_Elbow & 10.97 & 11.23 & 11.54 & 11.25 & 0.29 \\
\hline Left_Forearm & 11.19 & 11.28 & 11.33 & 11.26 & 0.07 \\
\hline Waist_Full & 38.27 & 38.34 & 38.16 & 38.26 & 0.09 \\
\hline Hips_Full & 39.23 & 39.31 & 39.06 & 39.20 & 0.13 \\
\hline Seat_Full & 38.63 & 38.74 & 38.67 & 38.68 & 0.06 \\
\hline Abdomen_Full & 38.74 & 38.74 & 38.65 & 38.71 & 0.05 \\
\hline Thigh_Left & 20.09 & 20.06 & 19.66 & 19.94 & 0.24 \\
\hline Thigh_Right & 20.07 & 20.16 & 19.74 & 19.99 & 0.22 \\
\hline Calf_Left & 14.63 & 14.73 & 14.62 & 14.66 & 0.06 \\
\hline Calf_Right & 15.04 & 15.03 & 14.93 & 15.00 & 0.06 \\
\hline Knee_Left & 14.57 & 14.69 & 14.41 & 14.56 & 0.14 \\
\hline Knee_Right & 14.39 & 14.43 & 14.19 & 14.34 & 0.13 \\
\hline
\end{tabular}

Table 6. Three Successive Scans of a Male Subject using the Sizestream Scanner converted to TC2 Format and Measured with TC2 Measurement Software

Table 7 displays the average measurements for the male scans acquired from the Sizestream scanner using Sizestream measurement software, the average measurements for the male scans acquired from the Sizestream scanner converted to TC2 binary format, and the average measurements of the male scans acquired by the TC2 NX-16 scanner as measured by the TC2 KX16 measurement software.

\begin{tabular}{|c|c|c|c|c|c|c|}
\hline & Sizestream Average & TC2 NX-16 Average & Sizestream - TC2 & Sizestream to TC2 Convert & Sizestream to TC2 Convert & Sizestream to TC2 Convert \\
\hline & Average & Average & Difference & Average & Difference from Sizestream & Difference from TC2 Scans \\
\hline \multicolumn{7}{|l|}{ Meas, Inches } \\
\hline Neck_Full & 18.64 & 17.67 & -0.97 & 17.62 & -1.03 & -0.06 \\
\hline Bust_Full & 41.35 & 41.67 & 0.32 & 41.62 & 0.27 & -0.05 \\
\hline Right_Biceps & 13.94 & 13.61 & -0.33 & 13.60 & -0.34 & -0.01 \\
\hline Right_Elbow & 11.85 & 10.94 & -0.91 & 11.23 & -0.61 & 0.30 \\
\hline Right_Forearm & 11.87 & 11.63 & -0.24 & 11.50 & -0.37 & -0.13 \\
\hline Left_Biceps & 13.59 & 13.46 & -0.13 & 13.07 & -0.52 & -0.39 \\
\hline Left_Elbow & 11.89 & 10.69 & -1.20 & 11.25 & -0.65 & 0.55 \\
\hline Left_Forearm & 11.65 & 11.24 & -0.41 & 11.26 & -0.39 & 0.02 \\
\hline Waist_Full & 38.30 & 38.57 & 0.28 & 38.26 & -0.04 & -0.32 \\
\hline Hips_Full & 39.33 & 39.55 & 0.22 & 39.20 & -0.13 & -0.35 \\
\hline Seat_Full & 38.72 & 38.89 & 0.17 & 38.68 & -0.04 & -0.21 \\
\hline Abdomen_Full & 38.63 & 39.05 & 0.43 & 38.71 & 0.08 & -0.34 \\
\hline Thigh_Left & 21.48 & 22.37 & 0.89 & 20.93 & -0.55 & -1.44 \\
\hline Thigh_Right & 21.50 & 22.20 & 0.70 & 20.98 & -0.52 & -1.22 \\
\hline Calf_Left & 14.88 & 15.08 & 0.21 & 14.66 & -0.22 & -0.42 \\
\hline Calf_Right & 15.12 & 15.30 & 0.18 & 15.00 & -0.12 & -0.30 \\
\hline Knee_Left & 15.14 & 15.82 & 0.69 & 14.56 & -0.58 & -1.26 \\
\hline Knee_Right & 14.85 & 15.64 & 0.79 & 14.34 & -0.51 & -1.30 \\
\hline
\end{tabular}

Table 7. Male Subject Average Measurement Comparisons for Sizestream Scans, TC2 Scans and Sizestream Scans converted to TC2 Format

Table 7 gives us a good snapshot of the three measurement averages for the male subject. Not only are there differences between the measurements retrieved by individual scanners and their respective measurement software packages, there are differences between scans acquired by one scanner and converted to a format that can be measured by another scanner manufacturer's software.

Table 8 contains similar information as in Table 7, but for the female subject. 


\begin{tabular}{|c|c|c|c|c|c|c|}
\hline & Sizestream Average & TC2 NX-16 Average & Sizestream - TC2 & Sizestream to TC2 Convert & Sizestream to TC2 Convert & $\begin{array}{l}\text { Sizestream to TC2 Convert } \\
\text { Difference from TC2 Scans }\end{array}$ \\
\hline \multicolumn{7}{|l|}{ Meas, Inches } \\
\hline Neck_Full & 15.26 & 15.50 & 0.24 & 15.44 & 0.18 & -0.06 \\
\hline Bust_Full & 39.40 & 39.95 & 0.55 & 39.86 & 0.46 & -0.10 \\
\hline Right_Biceps & 11.40 & 12.72 & 1.33 & 12.28 & 0.88 & -0.44 \\
\hline Right_Elbow & 10.94 & 10.11 & -0.83 & 10.57 & -0.37 & 0.46 \\
\hline Right_Forearm & 10.41 & 10.07 & -0.34 & 10.24 & -0.17 & 0.17 \\
\hline Left_Biceps & 12.11 & 12.26 & 0.15 & 11.81 & -0.30 & -0.45 \\
\hline Left_Elbow & 10.98 & 10.63 & -0.35 & 10.49 & -0.49 & -0.14 \\
\hline Left_Forearm & 10.33 & 10.50 & 0.17 & 9.95 & -0.38 & -0.55 \\
\hline Waist_Full & 36.10 & 35.55 & -0.55 & 35.77 & -0.33 & 0.22 \\
\hline Hips_Full & 38.76 & 38.80 & 0.04 & 38.65 & -0.11 & -0.15 \\
\hline Seat_Full & 38.54 & 38.76 & 0.22 & 38.54 & 0.00 & -0.22 \\
\hline Abdomen_Full & 37.23 & 35.65 & -1.58 & 36.20 & -1.03 & 0.55 \\
\hline Thigh_Left & 20.79 & 21.05 & 0.27 & 20.86 & 0.07 & -0.19 \\
\hline Thigh_Right & 20.36 & 20.43 & 0.07 & 20.38 & 0.02 & -0.05 \\
\hline Calf_Left & 13.69 & 13.89 & 0.20 & 13.56 & -0.13 & -0.34 \\
\hline Calf_Right & 13.37 & 13.61 & 0.25 & 13.24 & -0.13 & -0.37 \\
\hline Knee_Left & 14.03 & 13.77 & -0.25 & 13.84 & -0.18 & 0.07 \\
\hline Knee_Right & 13.64 & 13.21 & -0.43 & 13.44 & -0.20 & 0.23 \\
\hline
\end{tabular}

Table 8. Female Subject Average Measurement Comparisons for Sizestream Scans, TC2 Scans and Sizestream Scans converted to TC2 Format

The measurement changes documented in Table 8 show differences between the scans and their various measuring programs, but their differences do not reflect the same pattern as for the male subject in Table 7.

\section{Discussion}

This has been an exercise involving two booth type 3D scanners, one from Sizestream and the other from TC2, their respective software measurement packages, and converting Sizestream scans to a TC2 binary format for use in the TC2 KX-16 software measurement package.

The subjects were scanned multiple times in both scanners. The results indicate differences between the two software measurement packages. This is true for measuring successive scans acquired by the same machine. Of course, it is always difficult to remain in the exact scanning position for multiple scan acquisitions. Arm positions inevitably changes, and so perhaps, does the angle of head elevation. These changes in positions directly affect the location of the measurement landmarks and hence the particular circumferential measurement values.

There are also similar measurement differences between scans from the Sizestream scanner converted to the TC2 binary format and measured with the TC2 KX-16 measurement software.

The question then is: Does it even matter?

Like most any question, the answer is: "It depends."

The commercial network in use today is set up to scan preoperative morbidly obese individuals that will be undergoing a weight loss surgical procedure. The best that can be hoped for given the size of their bodies are gross measurements based on fairly consistent landmarks. It is not uncommon to manually move landmarks within the software measurement package to achieve this.

These individuals return for postoperative periodic postoperative visits and are typically scanned at 3 month, 6 month and 1 year after surgery intervals. Their bodies experience massive weight loss during the first 3 months, with weight loss continuing to occur thereafter at a slower rate, albeit still significant. These relative measurement changes appear to be something that both scanners document well.

The scanners are thus used to track gross circumferential measurement changes that accompany weight loss surgery. Specific circumferential measurement accuracy is not as important as the relative change in the measurements that are extracted, recorded and presented to the individual.

However, other applications might not have the luxury of comparing such dramatic measurement changes over time. Here is where one needs to be more careful. 
A business that scans thin and shapely bodies in order to construct made-to-fit swimwear such as bikinis or briefs might have to think hard about using two separate scanners and two separate measurement software packages. The measurement discrepancy between the two manufacturers may be too great for this application.

There is one area in this analysis of two separate scanner manufacturers and two separate measurement software packages that was not investigated. It is becoming more and more important as new ways to categorize obesity are being researched.

This is the area of volume and surface area calculations, including torso volume and surface area. At present, the interest has been in tracking and documenting circumferential measurement changes as an individual undergoes massive weight loss. It is argued here that for this application, relative measurement changes are more important than accurate measurements, hence two different scanners and one measurement software package, including conversion utilities can be implemented with a fair degree of confidence.

To calculate new multidimensional obesity indicators that use torso volume and torso surface area will require more consistency than what has been found for circumferential measurements. Circumferential measurements are generally created by locating fairly complex landmarks on the 3D body model. Slight differences in landmark locations as a result of changes in the scanning position will result in inconsistent circumferential measurements, even between two successive scans from the same scanner manufacturer. This is understood.

Fortunately, multidimensional information such as torso volume and torso height require only two landmarks: "Back of Neck" and "Crotchpoint." If these are accurately located and the dimensions of the torso, including the shoulders are similar between the 3D body models created by separate scanner manufacturers, there could be multidimensional consistency across scanning platforms.

It is important that 3D body models acquired by 3D booth scanner manufacturers be consistent and as interchangeable as possible. This exercise has showed that at least for the current application, by and large they are.

3D booth scanners and their measurement software packages need to act as reference platforms as new, more mobile 3D scanning technologies begin to proliferate. 